vitamin $\mathbf{C}$ in apples is retained on cooking, and the largest amounts of this vitamin occur in cider varieties. J. D. Bryan reports that the organic acid in plums and apples is almost all malic, in black currants chiefly citric, whereas gooseberries and tomato have a mixture of the two. Some potato varieties blacken on cooking, and have unsuitable texture; A. Pollard, M. E. Kieser and B. A. Crang show that cooking quality is mainly dependent on site, and the correction of manurial deficiencies improves the quality if its initial level was sufficiently high.

It seems appropriate that the report should close with a historical account, by R. W. Marsh, of the advisory agricultural services of the University of Bristol, which have been in operation since 1912 ; they have gradually gained the increasing confidence of farmer and grower, and should proceed to an even more useful future under the National Agricultural Serỵice.

\section{INTERNATIONAL ASPECTS OF THE RADIO-FREQUENCY SPECTRUM}

$\mathrm{D}$ URING the summer of 1947 , a series of International Telecommunication and Radio Conferences were held at Atlantic City, U.S.A., and the proceedings and conclusions of these have recently been published from the headquarters of the Inter. national Telecommunications Union at Berne, Switzerland. The object of these conferences was to revise the radio-communication regulations and the convention last formulated at Cairo in 1938 (see Nature, 141, 195; 1938), and to re-plan the allocation of radio frequencies for the many and varied applications in use at the present time. A summary of the findings of the Atlantic City Conferences, which were attended by nearly thirty British delegates under the leadership of Sir Stanley Angwin, is given in the April issue of the Wireless World.

Since the drafting of the Cairo regulations, the radio-frequency spectrum has been extended very considerably at the high-frequency end, while many fresh applications have arisen for which it is necessary to find frequencies either for exclusive use or for sharing with other services in the same or other parts of the world. Under the new regulations, specific provision is made for radio navigation systems, for radio aids to meteorology and for the transmission of standard frequencies of very high accuracy. In addition, certain limited bands have been designated for industrial, scientific and medical equipment: for Great Britain, and in some cases elsewhere, the frequencies assigned for these purposes are $13 \cdot 56$, $27 \cdot 12,40 \cdot 68,2450$ and $5850 \mathrm{Mc} / \mathrm{s}$. Within these bands, any emission from apparatus used for industrial, scientific and medical purposes enjoys priority over other services operated within the bands. Elsewhere in the spectrum, all such apparatus must presumably be screened or operated in such a manner as to avoid any interference with other radio services.

For the purpose of frequency allocations for the many types of communication, broadcasting, radar and navigational aids, the world was divided at Atlantic City into three regions. Region 1 comprises Europe, the U.S.S.R. territory outside Europe, the Mongolian Republic and Asia Minor and Africa; Region 2 covers the whole of the western hemisphere from Greenland to Hawaii ; while Region 3 comprises Australia, New Zealand, Oceania and that part of Asia not included in Region 1 . It has also been found necessary to re-define and extend the zone in which certain frequencies are allocated for Tropical Zone broadcasting.

A most useful guide to the radio frequency allocations made at Atlantic City has been issued by the Radio Corporation of America in the form of a coloured chart. This chart covers the spectrum between $10 \mathrm{kc} . / \mathrm{s}$. (wave-length $30 \mathrm{~km}$.) and more than 30,000 Mc./s. (wave-length $1 \mathrm{~cm}$.) ; and it shows for each of the three regions described above the bands of frequencies proposed for twenty-three different services. It is to be noted that no specific allocations are yet proposed above 10,500 Mc./s., such higher frequencies being still regarded as for experimental purposes. While some of the allocations are already in being, it is recommended that the provisions become effective during 1949. One of the most important outcomes, however, of the Atlantic City conferences was the decision to set up an International Frequency Registration Board, which has already begun its task of examining all notifications of the proposed use of frequencies with the view of including those approved in the Master International Frequency Register. In addition to dealing with the allocation of frequencies, the new regulations contain a number of new definitions of the terms now used in radio engineering and scientific work, and also a revised classification of the various portions of the radio spectrum, and of the types of transmission and the systems of modulation now in common use.

Bearing in mind the extent and complexity of modern telecommunications technique, it must be a source of satisfaction to all those who participated in the conferences that such a large measure of agreement has been obtained on the methods of conducting world-wide radio communications.

\section{FORTHCOMING EVENTS}

\section{Monday, May 31}

ROYAL Grographical Societr (at Kensington Gore, London S.W.7), at 5.30 p.m.- "Photo-Canada" (Kodachrome Film with Sound Commentary).

Wednesday, June 2-Saturday, June 5

TExTILE INstrutute (at Buxton).--Conference on "The Organisation of the Textile Industry and Textile Production".

\section{Thursday, June 3}

ROYAI SOcIETY (at Burlington House, Piccadilly, London, W.1) at 4.30 p.m.-Messrs. E. R. Andrew, M. Desirant and D. Shoenberg. "The Intermediate State of Superconductors".

ChEMTCAL Society (at Burlington House, Piccadilly, London, W.1), at 5.15 p.m.-Annual General Meeting.

Chemionl Society (at the Roval Institution, 21 Albemarle Street, London, W.1), at 7.30 p.m.-Prof. L. C. Pauling, For.Mem.R.S. "The Modern Theory of Valeney" (Liversidge Lecture).

\section{Friday, June 4}

Phystcal Society (in the Lecture Theatre, Science Museum, Exhibition Road, London, S.W.7), at 5 p.m.-Sir George Thomson, F.R.S.: "The Growth of Crystals" (32nd Guthrie Lecture).

GEoLogists' Association (at the Geological Society, Burlington House, Piccadilly, London, W.1), at 6 p.m.-Dr. F. J." North: "A Cave near Aberdare, Glamorgan; Geological Notes and Queries".

Cave near Aberdare, Glamorgan; Geological Notes and Queries" Reynolds Hall, College of Technology, Manchester), at 6.30 p.m. Mr. L. C. Jesty : "Television".

\section{APPOINTMENTS VACANT}

APPLICATIONS are invited for the following appointments on or before the dates mentioned

SECRETARY AND REGISTRAR-The Secretary and Registrar, University College of North Wales, Bangor (June 5). 